\title{
The failed reasons of Ralph Lauren rugby and its re- launching marketing strategy
}

\begin{abstract}
Many fashion brands closed their sub-brands and side-lines in recent years, such as Jack wills for Au bin \& Wills, Ralph Lauren of Ralph Lauren Rugby. It appears that the economic depression and the customers increasing demands impact greatly on the market, and not all the fashion styles are popular in the fashion market. Hence, it is necessary to take a look at the marketing strategies to analyze the reasons why these fashion brands were doomed for failure and try to put forward some useful marketing strategies to tackle the challenges and problems.
\end{abstract}

In this essay, the main topic will be focus on the reasons for failed of Ralph Lauren Rugby. The position of the brand reflected in the advertisement does not appeal to its young targeted customers as much as its competitors and the preppy style is not popular anymore, what is worse, the retailers are more interested in the luxury brand business. In accordance with 4Ps theory, the solution of Rugby's dilemma to re-position the advertising with a relaxing and fashionable style and let a popular celebrity become the 'face' of the brand, the re-formulation of the price range is also an indispensable factor.
Volume 2 Issue 4 - 2017

\author{
Yuyao Zhao \\ Shanghai University of Engineering Science, China
}

Correspondence: Yuyao Zhao, Fashion marketing and branding, Shanghai University of Engineering Science, China, Email hanxi.aogeng@163.com

Received: June 26, 2017 | Published: August 15, 2017

\section{Introduction}

In early 2013, Ralph Lauren's younger prep brand Rugby is set to close its stores and online shop, not only that, the competitor of Ralph Lauren Rugby, Jack wills also announced to shut down its sister brand: Au bin \& Wills Sebra. ${ }^{1}$ It seems that the preppy style is not popular in recently years, and the preferences of young consumers are increasing rapidly change, the visibility and influence of these prep brands are not so high. When the economy is increasing, the luxury brands will create a new sub-brand with a rising market; during the economic downturn, it will concentrate on the business of the strength of the strongest brand, so many luxury brands strongly focus on their main brand on business and closed their sub-brand.

Buil ${ }^{2}$ found that advertising and sales promotions can influence permanent sales from marketing actions. Compared with other marketing activities, consumption on promotions and advertising are important. So the promotion can affect the brand popularity. Moreover, a sub-brand advertising product-specific relate to the parent brand generally, and the sub-brand should focus on the value by describing offerings, structuring and refining offerings. Therefore, the promotion method and how to separate from the parent brand affects are important to analysis.

This report will examine the reasons of why Ralph Lauren Rugby is failure, then according to 4Ps theory, puts forward some marketing strategies to re-launching this fashion brand.

\section{The failed reasons}

\section{Promotion}

Ralph Lauren Corporation was founded by American designer Ralph Lauren of the Polo Ralph Lauren company in 1967, the well known flagship brand is Polo Ralph Lauren Sebra. ${ }^{1}$ However, the prep young brand Ralph Lauren Rugby was closed in early 2013. The clothing style are preppy style, the popularity are less than the parent brand, even the Price William and Harry are the loyal fans and have namely "The Tweed Run" activity in London recently. Because of Rugby always associate with the parent brand Ralph Lauren and it is easy to make customers cannot distinguish this brand, also never enter the China market, so the popularity is not so famous. Moreover, the well known competitors like Tommy Hilfiger do the advertising and promotion well, but the advertising of Rugby are not suitable for the brand position and fashion trends. These all demonstrate that the promotion strategy is the failed reason of Ralph Lauren Rugby.

Sales promotions play a key role in communication programs and marketing mix that effect brand equity. In contrast, different types of promotional tools like monetary and non-monetary promotions probably have different influence on sales or brand equity. Sales promotions usually concentrate on monetary promotions, like price discounts and gift card. However, some empirical evidence indicates that monetary promotions have a negative effect on brand equity. The main reasons are the reduction in the internal reference price Buil. ${ }^{2}$ But Rugby use a monetary promotion, only those who buy enough Ralph Lauren products can purchase the Rugby; this strategy can easily make the customers lose their interests in the brand. Meanwhile, advertising is one of the promotion methods, which is an effective way to convey functional and emotional values of the brand. Huge advertising investments can promote the brand's recognition and popularity, and expand the frequency of the brand appearance. That means the higher advertising cost is, the higher brand awareness levels are likely to be Buil. ${ }^{2}$

Compared with Ralph Lauren Rugby, its competitors like Tommy Hilfiger and American eagle outfitters have many much more accurate positioning advertisements.

According to Table 1, Tommy Hilfiger and American eagle outfitter clothing style as preppy style too, but the advertising gives the impression of youth and fashion, colorfulness and relaxation, as well as keeping up with the latest fashion trends, the consumers are likely 
to get attracted but this kind of advertising and make the decision to purchase. While the advertising of Rugby shows its clothing style are outdated, and the young consumer do not like this design and style, and the young consumer customers are likely to feel like they are Table I Comparative advertising still in the school and strictly supervised in the clothes. Therefore, the advertising position of Ralph Lauren Rugby is not successful in attracting the consumers' attention and preferences.

Brand
Advertising
Analysis
Failers focus
or the Ralph Lauren Rugby, the retailers play a key role in the
le marketing strategies and sales. There is sufficient evidence
onstrates that some retailers want to create their own brand,
ad of just being agent retailers, they want to master brand in
rns to its main business, it appears that the retailers' sales focus
the high street move to luxury market level; this might have led
Ralph Lauren Rugby's collapse.

Good Brands can make retailers attract customer traffic and build loyalty to the shops, as well as help build a lower-price image for retailers and improve their bargaining power of manufacturers and producers of main international brands. Nerveless, more and more retailers start to focus on actively marketing its own brand stores rather than manufacturers' brands as distributors, thus a lots of brands' retail aspects are facing some problems. If retailers do not want to sales the brand that do not belong and sell their own brand, many fashion brands would be greatly affected. Additionally, retailing is the key factor between consumption and production, and is practically related to its relations with customers.

In order to determine the retail offer, lots of retailers are cultivating a whole brand image and identity that increasingly supply the degree of marketplace differentiation Park. ${ }^{3}$ More retailers are trying to invest into increasing number of activities, which permit them to become corporate brands of their own; this measure is not conducive to lots of brands who have agent's retailers. The purpose of the retailers is to achieve a 'bundle' of activities and services, which offer 'added value' to the consumer impression. However, it also coordinates strategic visual with its internal culture and external image, and then the retailers eventually have become the brand Park. ${ }^{3}$ What is more, retailers have relationships with promotions, they are able to make decisions on promotions, promotions' effect for a retailer compared with promotions affect for a manufacturer are totally different Ailawadi. ${ }^{4}$ As the retailers can change and decide the advertising or promotion strategies, so it will make the image of the brand itself and retailers itself have the difference between the decision to produce the brand image, then consumers would be confused the about the brand image.

\section{Brand strategy}

\section{Promotion}

Promotional efforts are generally considered being as an effective tool of managing brands, such as feature advertising, in-store display and temporary price reductions-a best known traditional promotional way. It is necessary for Rugby to elect a suitable promotional strategy. 4Ps theory includes promotion, place, price and production; this essay will concentrate mainly on promotion part.

The promotion mix is usually used by a firm as a combination of promotional tools, promote services then convey a message to customers. The four standard factors promotion mix are advertising, public relationships, personal selling and sales promotion Posner. ${ }^{5}$ Advertising can build brand awareness, strong links and unique associations in consumers' memory, and provides positive brand feelings and judgments. To achieve these purposes, the advertising needs a suitable design and strategy. Indeed, one of the main effective advertising strategies is creative strategy; creative strategy can contribute to the ability of creating brand association. Therefore, the higher investment is in brand advertising, the stronger and more brand image will be related to the consumer's impression Buil. ${ }^{2}$

From this perspective, the previous advertising of Ralph Lauren Rugby did not reflect the brand positioning and values reflected, it seems not like the consumers position is aimed at youngsters between 16-25years old. To solve these problems, the first thing to do is adjust the brand position, the key to communicating the message to the market is to develop and create powerful and impressive vision images to attract more customers. According to Jobling ${ }^{6}$ for fashion trends in 2015, the advertising position of rugby can be colorfulness, self-expression and freedom. A method to express themselves to other people is large character prints, such as the latest fashion pattern and letter which can express their emotions and thoughts. Secondly, one technique strategy that can increase the number of consumers is to employ a celebrity to become the "face" of Rugby. The purpose of celebrity endorsement is the celebrity personality will directly refer to the brand image and identity in the marketplace Posner. ${ }^{5}$ Due to the Ralph Lauren Rugby's brand position, which is preppy style and young, the celebrity choice should be the idol of young people or related to the fashion industry, for example: In the UK market, one direction is the best choice, in the US, Taylor Swift is one of the most popular singers among the young persons. These measures can help Rugby re-launch their brand images and attract more retailers.

However, only changing the promotion is not enough, the other three points also should be mentioned. Many researches reveal that promotion effectiveness is usually not symmetric, higher quality promotions may have a disproportionate influence. That is to say when a sub-brand is newly launched, the brand positioning cost can 
be inpropotionally high. While the brand awareness still ages behind, just like the problem Rugby was faced with.

Therefore, the first essential thing is to cancel the strategy that only the customers who purchase enough Ralph Lauren products have the right to buy Rugby's products, and come up with some special sales discount. The second measure is re-position the price of Rugby and decided which marketplace is most suitable to re-launch it. Price architecture can be divided into three parts: low price points, medium price and high price points. Posner ${ }^{5}$ And Rugby can positioned at medium price point, meaning each shirt cost about $£ 50-99$, because most of the target customers are young people, they usually do not have the consumption ability to buy top brand expensive goods. Meanwhile, understanding the consumers' notions of value is significant, as well as paying attention to the competitor's pricing within the market, as well as paying attention to the competitor's pricing within the market.

\section{Conclusion}

Ralph Lauren is famous for its classic Polo T-shirts and the general marketing strategy is successful, given the brand popularity around the world. However, the young prep brand Ralph Lauren Rugby has already closed its stores and online shop in early 2013, Sebra ${ }^{1}$ so there is the need to analyze the reason behind the failure.

Obviously, most customers regard price promotions as a opportunity to buy high quality brands Bronnenberg. ${ }^{7}$ Therefore, the high price with the great promotion strategies can successful. By contrast, Rugby's promotion method is not so attractive; they even do not enter the Chinese market. The positioning of the advertising is not suitable and accurate enough for their target customers, compared with the advertising of its competitor, it focuses on preppy style shooting, and this makes it look like outdated and grave. Meanwhile, the price of position is not good enough either, the retailers are more concentrated on the luxury brand level. To re-launch this brand, creating a new fashionable and creative advertising according to fashion trends of 2015 is essential, as well as inviting a celebrity to represent the brand's image, the further steps can be canceling the limitation of purchasing and re-positioning the price at medium price points. The adoption of other good promotion methods would be great too.

The limitation of this essay is that it only emphasizes the promotion strategy; the other three elements of 4Ps are also worth paying attention to. ${ }^{8,9}$

\section{Acknowledgements}

None.

\section{Conflict of interest}

Author declares there is no conflict of interest in publishing the article.

\section{References}

1. Sebra M. Sad But True: Rugby Ralph Lauren to Close. 2012.

2. Buiil I, Chernatony L, Eva Martinez. Examining the role of advertising and sales promotions in brand equity creation. J Business Research. 2013;66(1):115-122.

3. Park JY, Park K, Dubinsky AJ. Impact of retailer image on private brand attitude: Halo effect and summary construct. Australian J Psychology. 2011;63(3):173-184.

4. Ailawadi KL, Harlam BA, César J, et al. Promotion Profitability for a Retailer: The Role of Promotion, Brand, Category, and Store Characteristics. J Marketing Research. 2006;43(4):518-535.

5. Posner H. Marketing Fashion. London: Laurence King Publishing Ltd; 2011.

6. Jobling A. Warner Bros: top trends for 2015. WGSN. 2013.

7. Bronnenberg BJ, Wathieu L. Asymmetric Promotion Effects and Brand Positioning. Marketing Science. 1996;15(4):379-394.

8. Slotegraaf RJ, Pauwels K. The Impact of Brand Equity and Innovation on the Long-Term Effectiveness of Promotions. J Marketing Research. 2008;45:293-306.

9. American Marketing Association. 2014. 